\title{
Discovery of 4-Pyridone Derivatives as Specific Inhibitors of Enoyl-Acyl Carrier Protein Reductase (Fabl) with Antibacterial Activity against Staphylococcus aureus
}

\author{
Sho Takahata, Maiko Iida, Takuji Yoshida, Ko Kumura, Hideo Kitagawa, \\ Shigeru Hoshiko
}

Received: October 30, 2006 / Accepted: December 22, 2006

(C) Japan Antibiotics Research Association

\begin{abstract}
Pyridone derivatives were identified as potent inhibitors of FabI, the enoyl-acyl carrier protein reductase in Escherichia coli and Staphylococcus aureus. 1-Substituted derivatives of a hit compound exhibited potent antibacterial activities against $S$. aureus. Target specificity of 4-pyridone derivatives was confirmed by the strong inhibition of lipid synthesis in macromolecular biosynthesis assay and also by the reduced antimicrobial activity against triclosan-resistant $S$. aureus isolates possessing a point mutation (Ala95Val) in FabI. Two 4-pyridone compounds exhibited strong antibacterial activities against 30 clinical isolates of methicillin-resistant S. aureus (MRSA) with $\mathrm{MIC}_{90}$ of 0.5 and $2 \mu \mathrm{g} / \mathrm{ml}$, respectively. Moreover, they retained activity against $S$. aureus with a mutation affecting FabI residue 204, which was recently found to be associated with triclosan resistance in clinical isolates of $S$. aureus. In conclusion, we have identified a novel chemical series, 4-pyridone derivatives, as specific inhibitors of FabI with potent antibacterial activity against $S$. aureus.
\end{abstract}

Keywords enoyl-acyl carrier protein reductase, FabI, 4-pyridone, inhibitor, Staphylococcus aureus, MRSA

S. Takahata (Corresponding author), M. Iida, T. Yoshida, K. Kumura, H. Kitagawa, S. Hoshiko: Pharmaceutical Research Center, Meiji Seika Kaisha, Ltd., 760 Morooka-cho, Kohoku-ku, Yokohama 222-8567, Japan, E-mail: sho_takahata@meiji.co.jp

\section{Introduction}

Fatty acid biosynthesis in bacteria is typically catalyzed by the type II fatty acid synthase system, which is made up of discrete enzymes, in contrast to the multifunctional type I fatty acid synthase found in mammals. Therefore, the enzymes of bacterial fatty acid synthesis are potential targets for the development of novel antibacterials with high selectivity [1]. Enoyl-acyl carrier protein (ACP) reductase, which catalyzes the last step in each cycle of fatty acid elongation, is a promising target because it plays a key role in the regulation of the pathway [2]. Two previous studies, one using a temperature-sensitive $f a b I$ mutant of Escherichia coli and another using enoyl-ACP reductase-specific inhibitors, demonstrated that the enoylACP reductase activity was essential for the survival of bacteria. Triclosan, widely used as a disinfectant agent with broad-spectrum antibacterial activity, was found to inhibit FabI, the enoyl-ACP reductase of E. coli [3] and Staphylococcus aureus [4, 5]. The anti-tuberculosis agent, isoniazid targets the FabI homologue (InhA) of Mycobacterium tuberculosis [6]. Diazaborines were also found to inhibit FabI [7]. Although an alternative enoyl-ACP reductase, FabK, which displays no significant sequence homology to FabI, was identified in Streptococcus pneumoniae, Enterococcus faecalis and Pseudomonas aeruginosa [8], genomic studies have revealed that most bacteria possess FabI as the sole enoyl-ACP reductase. There are several recent reports of FabI inhibitors with antibacterial activity against $S$. aureus [9 11], or a novel FabK inhibitor with antipneumococcal activity [12]. 
However, there are very few reports of inhibitors with proof of target specificity.

In the present study, we report a novel chemical series, 4-pyridone derivatives, as the FabI-directed antibacterial agent with potent antibacterial activity against $S$. aureus, including methicillin-resistant $S$. aureus (MRSA).

\section{Materials and Methods}

\section{Bacterial Strains and Reagents}

S. aureus ATCC 29213 and E. coli DH5 $\alpha$ were obtained from the American Type Culture Collection and Toyobo Co., Ltd., respectively. S. aureus strains N315, RN4220, and MF535 were obtained from the culture collection of Meiji Seika Kaisha. E. coli W4680 and WZM120 (acrAB inactivated strain from W4680) were kindly provided from Dr. Hiroshi Nikaido [13]. Thirty clinical isolates of MRSA included in the antibacterial activity assay were collected from various hospitals across Japan in 2001. The following agents were used in this study: compound $\mathbf{2}$, compound $\mathbf{3}$ (Bionet Research); cerulenin, triclosan (Sigma); vancomycin (Shionogi \& Co., Ltd.). Linezolid was synthesized at the Pharmaceutical Research Center of Meiji Seika Kaisha, Ltd. The radiolabeled compounds, $\left[2-{ }^{14} \mathrm{C}\right]$ thymidine, [U- $\left.{ }^{14} \mathrm{C}\right]$ uridine, L- $\left[4,5-{ }^{3} \mathrm{H}\right]$ leucine, $\left[2-{ }^{14} \mathrm{C}\right]$ acetic acid and $N$-acetyl-D- $\left[1-{ }^{14} \mathrm{C}\right]$ glucosamine were from Amersham Biosciences Corp.

\section{Antimicrobial Susceptibility Testing}

MICs were determined by the agar dilution method according to the Clinical and Laboratory Standards Institute (formerly the National Committee for Clinical Laboratory Standards) [14]. The compounds $\mathbf{2}$ and $\mathbf{3}$ were dissolved in DMSO, and serial two-fold dilutions were prepared from each stock solution before use.

\section{Selection and Characterization of Triclosan-resistant Mutants}

For isolation of triclosan-resistant derivatives of $S$. aureus ATCC 29213 and MF535, overnight culture of cells, grown in Mueller-Hinton broth, were plated on to Mueller-Hinton agar containing 0.25 or $1 \mu \mathrm{g} / \mathrm{ml}$ of triclosan. After incubation at $35^{\circ} \mathrm{C}$ for 48 hours, single colonies were selected for nucleotide sequence analysis of the fabI gene. For this purpose, the full-length $f a b I$ gene from each clone was amplified by PCR using the following two deoxyoligonucleotide primers: 5'-TGGGATTAGATATTCTATCC-3' and 5'-TGCTCACATATATGATAACG-3'.

\section{Construction of Expression Vectors and Purification of} FabI

The E. coli fabI gene was amplified by PCR from the $E$. coli $\mathrm{DH} 5 \alpha$ using the following two deoxyoligonucleotide primers: 5'-TTAAAGCCATGGGTTTTCTTTCCGGTAA$3^{\prime}$ and 5'-CAACAGTCTAGAAGTTTCAGTTCGAGTTCG-3'. The PCR product was digested with $N c o$ I and $X b a \mathrm{I}$, and cloned into the corresponding restriction sites of pBAD/Myc-HisB (Invitrogen Corp.). The substitution of glycine 93 by valine was carried out using the QuikChange Site-Directed Mutagenesis Kit (Stratagene) and the following deoxyoligonucleotide primers: 5'-CGTACACTCTATTGTTTTTGCACCTGGC-3' and 5'-GCCAGGTGCAAAAACAATAGAGTGTACG-3'. The fabI gene of $S$. aureus $\mathrm{N} 315$ was amplified by PCR using the deoxyoligonucleotide primers 5'-ATGTTAAATCTTGAAAACAA-3' and 5' 5'TATTTAATTGCGTGGAATC-3' $^{\prime}$. The PCR products were cloned into pTrcHis-TOPO (Invitrogen Corp.). Resulting plasmids containing the fabI gene of $E$. coli or $S$. aureus were transformed into $E$. coli TOP10. Cells harboring the fabI plamids were grown, harvested after the induction of gene expression and cellfree extracts were prepared by sonication. His-tagged FabI proteins were purified using Ni-NTA agarose column (QIAGEN). The purified recombinant proteins were exchanged into $0.1 \mathrm{M}$ sodium phosphate buffer ( $\mathrm{pH}$ 7.4) by dialysis and stored at $-80^{\circ} \mathrm{C}$ until use.

\section{FabI Inhibition Assay}

Assays were performed in 96-well plate format in a final assay volume of $100 \mu$ l. For E. coli FabI inhibition assay, the reaction mixture consisted of $0.1 \mathrm{M}$ sodium phosphate buffer (pH 7.4), $0.25 \mathrm{mM}$ crotonoyl-CoA, $0.4 \mathrm{mM}$ NADH, and $50 \mu \mathrm{g} / \mathrm{ml}$ of purified FabI. For $S$. aureus FabI inhibition assay, the reaction mixture consisted of $0.1 \mathrm{M}$ sodium $\mathrm{N}$-(2-acetamido)-iminodiacetic acid (pH 6.5), $0.25 \mathrm{mM}$ crotonoyl-CoA, $0.4 \mathrm{mM} \mathrm{NADPH}$, and $100 \mu \mathrm{g} / \mathrm{ml}$ of purified FabI [5]. Reaction was initiated by the addition of crotonoyl-CoA, and the decrease in absorbance at $340 \mathrm{~nm}$ caused by the oxidation of NADH or NADPH was measured for 10 minutes at room temperature. IC $_{50}$ was defined as the concentration of inhibitor giving a $50 \%$ reduction in the enzymatic activity.

\section{Macromolecular Biosynthesis Assay}

Overnight culture of $S$. aureus RN4220 was inoculated in fresh LB broth and incubated at $37^{\circ} \mathrm{C}$ for 4 hours to obtain an exponentially growing inoculum. Compounds at a final concentration of MIC were added to a $2 \mathrm{ml}$ aliquot of cell culture before the addition of each radioactive precursor for macromolecular synthesis. $\left[{ }^{14} \mathrm{C}\right]$ thymidine, $\left[{ }^{14} \mathrm{C}\right]$ uridine, 
$\left[{ }^{3} \mathrm{H}\right]$ leucine, $\left[{ }^{14} \mathrm{C}\right]$ acetic acid and $\left[{ }^{14} \mathrm{C}\right] N$-acetylglucosamine were used for determining the biosynthesis of DNA, RNA, proteins, lipids and cell wall, respectively. After 30 minutes incorporation, $0.2 \mathrm{ml}$ of the cell suspension was transferred to $2 \mathrm{ml}$ of $10 \%$ trichloroacetic acid to precipitate macromolecules. Biomass were filtered on GF/C glass filter (Whatman) and washed twice with an excess volume of 5\% trichloroacetic acid. The radioactivity of the dried filter was measured using a liquid scintillation counter and data were expressed as percentage inhibition of incorporation compared with the drug-free control. Experiments were performed in duplicate and the results were expressed as mean values.

\section{Results}

\section{Identification of the Inhibitors of FabI}

High-throughput screening of about 100,000 compounds from our library (containing natural products and synthetic compounds) resulted in the identification of compound $\mathbf{1}$ as a potent inhibitor of E. coli FabI (Fig. 1). Chemical modifications revealed that the 2,6-dichlorobenzyl group at 3-position and the methyl group at 2-position of 4-pyridone ring were essential for inhibiting the FabI enzyme activity [15]. Among various 1-substituted 4-pyridone derivatives, the compounds $\mathbf{2}$ and $\mathbf{3}$ (Fig. 1) inhibited the FabI activity more effectively than the compound $\mathbf{1}$ (Table 1). Although compounds $\mathbf{2}$ and $\mathbf{3}$ exhibited poor antibacterial activity against E. coli strains, they exhibited 16 to 32 -fold and 8 -fold stronger antibacterial activity, respectively, against S. aureus than the compound $\mathbf{1}$.

\section{Mode of Action}

The substitution of glycine 93 by valine (Gly93Val) in $E$. coli FabI was reported to confer resistance to triclosan [3]. Accordingly, compounds $\mathbf{2}$ and $\mathbf{3}$, as well as triclosan, inhibited the mutant FabI, FabI(Gly93Val), less effectively than the wild type FabI (Table 1). The macromolecular synthesis assay using $S$. aureus RN4220 demonstrated that the compound 3 strongly inhibited the incorporation of acetic acid at MIC (Fig. 2A), indicating this compound was a specific inhibitor of lipid biosynthesis. Similar patterns of inhibition were observed with another FabI inhibitor, triclosan, and also by cerulenin, an inhibitor of the condensing enzymes FabB and FabF in bacterial fatty acid biosynthesis (Fig. 2B, C).
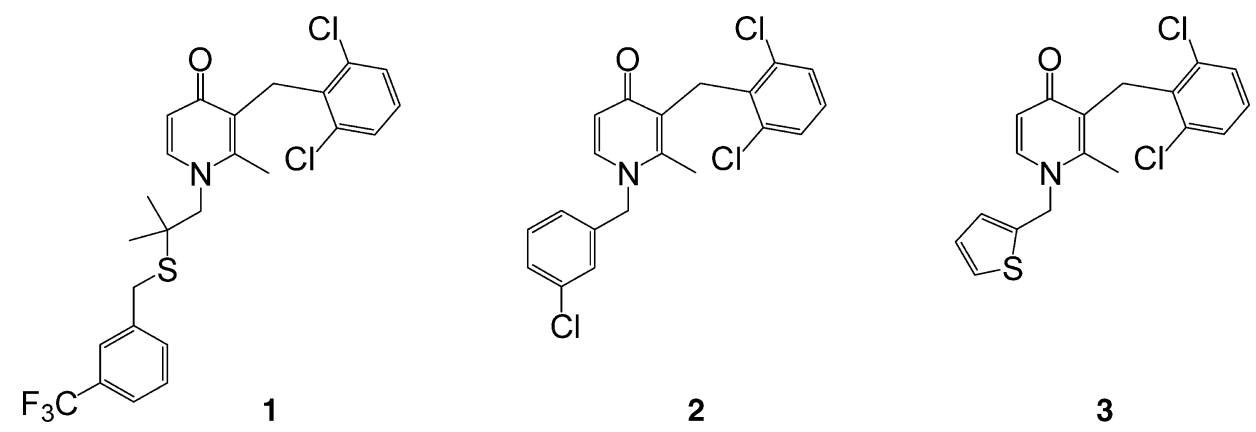

Fig. 1 Chemical structures of the novel Fabl inhibitors.

Table 1 Enzyme inhibitory activities and MICs of Fabl inhibitors

\begin{tabular}{|c|c|c|c|c|c|c|c|}
\hline \multirow{2}{*}{ Compound } & \multicolumn{3}{|c|}{$\mathrm{IC}_{50}(\mu \mathrm{M})$} & \multicolumn{4}{|c|}{$\mathrm{MIC}(\mu \mathrm{g} / \mathrm{ml})$} \\
\hline & $\begin{array}{c}\text { E. coli } \\
\text { Fabl wt }\end{array}$ & $\begin{array}{c}\text { E. coli } \\
\text { Fabl(Gly93Val) }\end{array}$ & $\begin{array}{l}\text { S. aureus } \\
\text { Fabl wt }\end{array}$ & $\begin{array}{c}\text { E. coli } \\
\text { W4680 }\end{array}$ & $\begin{array}{c}\text { E. coli } \\
\text { WZM120* }\end{array}$ & $\begin{array}{c}\text { S. aureus } \\
\text { ATCC } 29213\end{array}$ & $\begin{array}{l}\text { S. aureus } \\
\text { RN4220 }\end{array}$ \\
\hline 1 & 1.8 & 3.7 & 1.6 & $>64$ & $>64$ & 8 & 8 \\
\hline 2 & 0.34 & 3.3 & 0.34 & $>64$ & 32 & 0.25 & 0.5 \\
\hline 3 & 0.40 & 38 & 0.35 & $>64$ & 32 & 1 & 1 \\
\hline Triclosan & 0.51 & 9.9 & 3.8 & 0.12 & 0.03 & 0.016 & 0.25 \\
\hline
\end{tabular}

* acrAB was inactivated from the parent strain, E. coli W4680. 
(A)

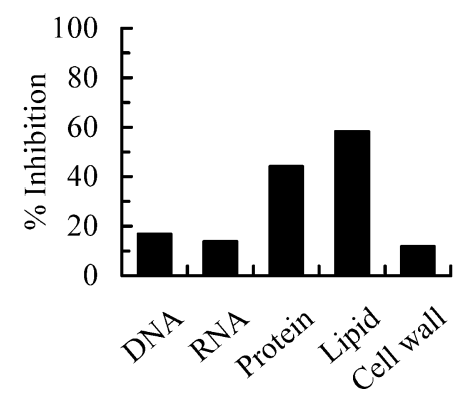

(B)

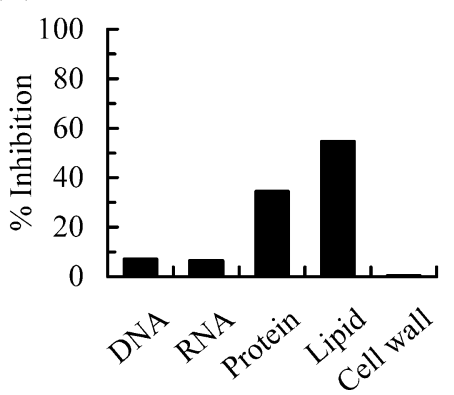

(C)

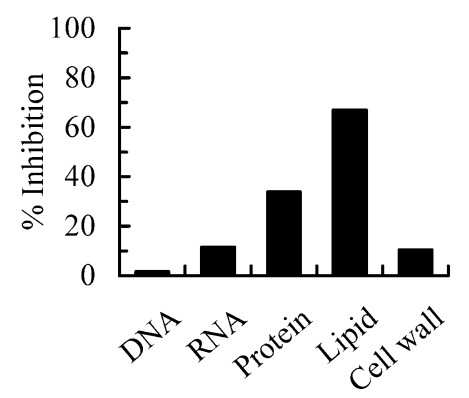

Fig. 2 Effect of bacterial fatty acid synthesis inhibitors on macromolecular biosynthesis in S. aureus.

Inhibitors were added at MIC for 30 minutes. (A) Compound 3: $1 \mu \mathrm{g} / \mathrm{ml}$, (B) Triclosan: $0.25 \mu \mathrm{g} / \mathrm{ml}$, (C) Cerulenin: $64 \mu \mathrm{g} / \mathrm{ml}$. Biosynthesis of DNA, RNA, protein, lipid and cell wall were determined as described in Materials and Methods. Experiments were performed in duplicate and the results were expressed as mean values.

Table 2 Antibacterial activities of compounds $\mathbf{2}$ and $\mathbf{3}$ against triclosan-resistant S. aureus isolates

\begin{tabular}{|c|c|c|c|c|}
\hline \multirow{2}{*}{ Strain } & \multirow{2}{*}{$\begin{array}{l}\text { Substitutions } \\
\text { in Fabl* }\end{array}$} & \multicolumn{3}{|c|}{$\mathrm{MIC}(\mu \mathrm{g} / \mathrm{ml})$} \\
\hline & & Compound 2 & Compound $\mathbf{3}$ & Triclosan \\
\hline S. aureus ATCC 29213 & none & 0.25 & 1 & 0.016 \\
\hline S. aureus ATCC 29213-m1 & Ala95Val & $>64$ & $>64$ & 2 \\
\hline S. aureus ATCC 29213-m2 & Phe204Ser & 0.5 & 1 & 1 \\
\hline S. aureus MF535 & none & 0.5 & 1 & 0.016 \\
\hline S. aureus MF535-m & Phe204Ser & 0.25 & 1 & 1 \\
\hline
\end{tabular}

* Amino acid sequences were compared with that of S. aureus N315 (GenBank accession no. BA000018).

\section{Antimicrobial Activities of 4-Pyridone Derivatives against Triclosan-resistant $S$. aureus}

To evaluate the target specificity more precisely, triclosanresistant $S$. aureus isolates were selected from strains ATCC 29213 and MF535 (MRSA). Two ATCC 29213 mutants (ATCC 29213-m1 and -m2) and one MF535 mutant (MF535-m) were obtained. Nucleotide sequencing of the $\mathrm{fabI}$ genes revealed that the FabI protein contained an alanine 95 to valine replacement (Ala95Val) in the ATCC 29213-m1 mutant, and a phenylalanine 204 to serine replacement (Phe204Ser) in the ATCC 29213-m2 and MF535-m mutants.

Table 2 summarizes the antibacterial activities of the 4pyridone derivatives against the triclosan-resistant mutants. As expected, the MIC for triclosan increased significantly for both the ATCC 29213-m1 and ATCC 29213-m2 mutants. Similar to triclosan, the MICs of the compounds 2 and 3 were also increased for the ATCC 29213-m1 mutant (Table 2). In contrast, the MICs of the 4-pyridone derivatives did not change for the ATCC 29213-m2 mutant expressing the FabI(Phe204Ser). Similar result was obtained from the triclosan-resistant MF535 isolate
Table 3 Antibacterial activities of compounds $\mathbf{2}$ and $\mathbf{3}$ and reference antibiotics against clinical isolates of MRSA

\begin{tabular}{lllc}
\hline \multirow{2}{*}{ Antibiotic } & \multicolumn{3}{c}{$\mathrm{MIC}(\mu \mathrm{g} / \mathrm{ml})$} \\
\cline { 2 - 4 } & $\mathrm{MIC}_{50}$ & $\mathrm{MIC}_{90}$ & Range \\
\hline Compound $\mathbf{2}$ & 0.25 & 0.5 & $0.12-0.5$ \\
Compound $\mathbf{3}$ & 1 & 2 & $1-2$ \\
Vancomycin & 1 & 1 & $0.5-1$ \\
Linezolid & 2 & 2 & $1-2$ \\
\hline
\end{tabular}

(MF535-m), which also contained the Phe204Ser mutation in the FabI.

Antibacterial Activity against Clinical Isolates of MRSA Antibacterial activities of the compounds $\mathbf{2}$ and $\mathbf{3}$ were evaluated with a panel of MRSA $(n=30)$ clinical isolates. As summarized in Table 3, the MICs of compounds $\mathbf{2}$ and $\mathbf{3}$ at which $90 \%$ of the isolates were inhibited $\left(\mathrm{MIC}_{90}\right)$ were 
0.5 and $2 \mu \mathrm{g} / \mathrm{ml}$, respectively. Notably, the antimicrobial activities of the 4-pyridone derivatives against the MRSA were comparable or superior to those of the vancomycin and linezolid.

\section{Discussion}

A spontaneous triclosan-resistant $E$. coli mutant was shown to possess a FabI enzyme in which the glycine 93 was substituted by a valine, i.e. FabI(Gly93Val) [3]. Enzyme inhibition assay revealed that the affinity of the 4-pyridone derivatives for this mutant FabI was weaker than that of the wild type enzyme (Table 1). This result strongly supports that the 4-pyridone derivatives are FabI-directed antibacterial agents. Alignment of the amino acid sequences of the E. coli and S. aureus FabI indicated that the position 93 in E. coli FabI corresponds to the position 95 in $S$. aureus FabI. Therefore, the poor inhibitory effect of the 4-pyridone derivatives on E. coli FabI(Gly93Val) would explain why 4-pyridone derivatives exhibited poor antibacterial activity against the $S$. aureus ATCC 29213-m1, which contains the homologous mutation (Ala95Val) in FabI.

Because of its broad-spectrum activity, triclosan is now widely used in household items and also in the clinical setting. However, recent reports warn that the widespread use of triclosan might select resistant strains. Indeed, AlDoori Z, et al. reported that 10 out of 232 clinical MRSA isolates $(4.3 \%)$ were resistant to triclosan (MIC: 1 to $4 \mu \mathrm{g} / \mathrm{ml}$ ) [16]. Characterization of the triclosan-resistant clinical isolates of $S$. aureus revealed that the resistance was mainly due to the replacement of the phenylalanine 204 to cystein in the FabI [17]. One of our spontaneously selected triclosan-resistant $S$. aureus mutants contained a point mutation in the $f a b I$ gene resulting in a FabI protein with a serine residue at position 204 in place of phenylalanine. In antimicrobial susceptibility test, the 4-pyridone derivatives inhibited the $S$. aureus mutants expressing the FabI(Phe204Ser), the ATCC 29213-m2 and MF535-m strains, as well as the parent strains with similar MICs. These results suggested that the mutation at position 204 of FabI, which is the mutation found in clinical isolates, did not affect the inhibitory activity of the 4pyridone derivatives. Therefore, we do not anticipate that the 4-pyridone derivatives will show any cross-resistance against the clinical isolates of triclosan-resistant $S$. aureus.

X-ray crystal structure analysis has identified that triclosan inhibits the FabI by forming a stable ternary complex, FabI-NAD ${ }^{+}$-triclosan [18]. Enzyme kinetic assay has revealed that one of our 4-pyridone derivatives (1-cyclohexylmethyl substituted compound [15]) inhibited the E. coli FabI in a competitive manner (data not shown), which is totally different from the way by which triclosan inhibits FabI. These results, together with the difference in susceptibility against the triclosan-resistant S. aureus mutants harboring FabI(Phe204Ser), suggest that the interaction of the 4-pyridone derivatives with the FabI is distinct from that of the triclosan. Further study is needed to identify the 4-pyridone derivative-binding site of the FabI.

In conclusion, we have discovered a novel chemical series of FabI-directed antibacterial 4-pyridone derivatives, with potent antibacterial activity against $S$. aureus.

Acknowledgments We thank Dr. Hiroshi Nose of Trans Genic Inc. for providing excellent technical advice.

\section{References}

1. Heath RJ, White SW, Rock CO. Lipid biosynthesis as a target for antibacterial agents. Prog Lipid Res 40: 467-497 (2001)

2. Heath RJ, Rock CO. Enoyl-acyl carrier protein reductase $(f a b I)$ plays a determinant role in completing cycles of fatty acid elongation in Escherichia coli. J Biol Chem 270: 26538-26542 (1995)

3. Heath RJ, Yu YT, Shapiro MA, Olson E, Rock CO. Broad spectrum antimicrobial biocides target the FabI component of fatty acid synthesis. J Biol Chem 273: 30316-30320 (1998)

4. Heath RJ, Li J, Roland GE, Rock CO. Inhibition of the Staphylococcus aureus NADPH-dependent enoyl-acyl carrier protein reductase by triclosan and hexachlorophene. J Biol Chem 275: 4654-4659 (2000)

5. Slater-Radosti C, Van Aller G, Greenwood R, Nicholas R, Keller PM, DeWolf Jr. WE, Fan F, Payne DJ, Jaworski DD. Biochemical and genetic characterization of the action of triclosan on Staphylococcus aureus. J Antimicrob Chemother 48: 1-6 (2001)

6. Quemard A, Sacchettini JC, Dessen A, Vilcheze C, Bittman R, Jacobs Jr. WR, Blanchard JS. Enzymatic characterization of the target for isoniazid in Mycobacterium tuberculosis. Biochemistry 34: 8235-8241 (1995)

7. Turnowsky F, Fuchs K, Jeschek C, Hogenauer G. envM genes of Salmonella typhimurium and Escherichia coli. J Bacteriol 171: 6555-6565 (1989)

8. Heath RJ, Rock CO. A triclosan-resistant bacterial enzyme. Nature 406: 145-146 (2000)

9. Heerding DA, Chan G, DeWolf Jr. WE, Fosberry AP, Janson CA, Jaworski DD, McManus E, Miller WH, Moore TD, Payne DJ, Qiu X, Rittenhouse SF, Slater-Radosti C, Smith W, Takata DT, Vaidya KS, Yuan CCK, Huffman WF. 1,4Disubstituted imidazoles are potential antibacterial agents 
functioning as inhibitors of enoyl acyl carrier protein reductase (FabI). Bioorg Med Chem Lett 11: 2061-2065 (2001)

10. Ling LL, Xian J, Ali S, Geng B, Fan J, Mills DM, Arvanites AC, Orgueira H, Ashwell MA, Carmel G, Xiang Y, Moir DT. Identification and characterization of inhibitors of bacterial enoyl-acyl carrier protein reductase. Antimicrob Agents Chemother 48: 1541-1547 (2004)

11. Payne DJ, Miller WH, Berry V, Brosky J, Burgess WJ, Chen E, DeWolf Jr. WE, Fosberry AP, Greenwood R, Head MS, Heerding DA, Janson CA, Jaworski DD, Keller PM, Manley PJ, Moore TD, Newlander KA, Pearson S, Polizzi BJ, Qiu X, Rittenhouse SF, Slater-Radosti C, Salyers KL, Seefeld MA, Smyth MG, Takata DT, Uzinskas IN, Vaidya K, Wallis NG, Winram SB, Yuan CCK, Huffman WF. Discovery of a novel and potent class of FabI-directed antibacterial agents. Antimicrob Agents Chemother 46: 3118-3124 (2002)

12. Takahata S, Iida M, Osaki Y, Saito J, Kitagawa H, Ozawa T, Yoshida T, Hoshiko S. AG205, a novel agent directed against FabK of Streptococcus pneumoniae. Antimicrob Agents Chemother 50: 2869-2871 (2006)

13. Ma D, Cook DN, Alberti M, Pon NG, Nikaido H, Hearst JE. Genes $a c r A$ and $a c r B$ encode a stress-induced efflux system of Escherichia coli. Mol Microbiol 16: 45-55 (1995)

14. National Committee for Clinical Laboratory Standards. Methods for dilution antimicrobial susceptibility tests for bacteria that grow aerobically: Approved standard M7-A6. National Committee for Clinical Laboratory Standards, Wayne, Pa (2003)

15. Kitagawa H, Kumura K, Takahata S, Iida M, Atsumi K. 4 Pyridone derivatives as new inhibitors of bacterial enoylACP reductase FabI. Bioorg Med Chem 15: 1106-1116 (2007)

16. Al-Doori Z, Morrison D, Edwards G, Gemmell C. Susceptibility of MRSA to triclosan. J Antimicrob Chemother 51: 185-186 (2003)

17. Fan F, Yan K, Wallis NG, Reed S, Moore TD, Rittenhouse SF, DeWolf Jr. WE, Huang J, McDevitt D, Miller WH, Seefeld MA, Newlander KA, Jakas DR, Head MS, Payne DJ. Defining and combating the mechanisms of triclosan resistance in clinical isolates of Staphylococcus aureus. Antimicrob Agents Chemother 46: 3343-3347 (2002)

18. Heath RJ, Rubin JR, Holland DR, Zhangs E, Snow ME, Rock CO. Mechanism of triclosan inhibition of bacterial fatty acid synthesis. J Biol Chem 274: 11110-11114 (1999) 